University of Wollongong

Research Online

Faculty of Engineering and Information

Faculty of Engineering and Information

Sciences - Papers: Part A

Sciences

$1-1-2012$

Impact of mains connected three-phase induction motor loading levels on network voltage unbalance attenuation

Upuli Jayatunga

University of Wollongong, jvupj453@uowmail.edu.au

Sarath Perera

University of Wollongong, sarath@uow.edu.au

Philip Ciufo

University of Wollongong, ciufo@uow.edu.au

Follow this and additional works at: https://ro.uow.edu.au/eispapers

Part of the Engineering Commons, and the Science and Technology Studies Commons

Research Online is the open access institutional repository for the University of Wollongong. For further information contact the UOW Library: research-pubs@uow.edu.au 


\title{
Impact of mains connected three-phase induction motor loading levels on network voltage unbalance attenuation
}

\begin{abstract}
Voltage unbalance $(\mathrm{VU})$ in power systems should be managed in a systematic manner in order to minimise its adverse effects on both customer equipment and supply utilities. It is a well known fact that three-phase induction motor performance can be significantly affected in the presence of supply voltage unbalance. It is also known that three-phase induction motors can help to reduce pre-existing network voltage unbalance levels. Recently undertaken research aligned with IEC/TR 61000-3-13:2008 Technical Report on voltage unbalance management (emission allocation and emission assessment) have quantified the contribution made by induction motors to the net voltage unbalance at a point of connection. It is perceived that loading level of three-phase induction motors will have an influence on this contribution. Hence, this study focuses on a sensitivity analysis of induction motor loading level on the voltage unbalance emission contribution to the point of connection. Simulation work undertaken indicates that increased loading levels on induction motors tend to exacerbate negative sequence voltage unbalance factor (VUF) at the point of connection in comparison to lightly loaded induction motors.
\end{abstract}

\section{Keywords}

network, levels, loading, motor, induction, phase, unbalance, three, attenuation, connected, voltage, mains, impact

\section{Disciplines}

Engineering | Science and Technology Studies

\section{Publication Details}

U. Jayatunga, S. Perera \& P. Ciufo, "Impact of mains connected three-phase induction motor loading levels on network voltage unbalance attenuation," in IEEE International Conference on Power System Technology (POWERCON), 2012, pp. 1-6. 


\title{
Impact of Mains Connected Three-Phase Induction Motor Loading Levels on Network Voltage Unbalance Attenuation
}

\author{
U. Jayatunga, Student Member, IEEE, S. Perera, Member, IEEE, and P. Ciufo, Senior Member, IEEE
}

\begin{abstract}
Voltage unbalance (VU) in power systems should be managed in a systematic manner in order to minimise its adverse effects on both customer equipment and supply utilities. It is a well known fact that three-phase induction motor performance can be significantly affected in the presence of supply voltage unbalance. It is also known that three-phase induction motors can help to reduce pre-existing network voltage unbalance levels. Recently undertaken research aligned with IEC/TR 61000-313:2008 Technical Report on voltage unbalance management (emission allocation and emission assessment) have quantified the contribution made by induction motors to the net voltage unbalance at a point of connection. It is perceived that loading level of three-phase induction motors will have an influence on this contribution. Hence, this study focuses on a sensitivity analysis of induction motor loading level on the voltage unbalance emission contribution to the point of connection. Simulation work undertaken indicates that increased loading levels on induction motors tend to exacerbate negative sequence voltage unbalance factor (VUF) at the point of connection in comparison to lightly loaded induction motors.
\end{abstract}

Index Terms-power quality, voltage unbalance, current unbalance, voltage unbalance emission allocation, voltage unbalance emission assessment, system inherent asymmetry, load asymmetry, induction motors

\section{INTRODUCTION}

A NALYSIS of load behaviour is an important aspect related to power system planning and operation. Mains connected induction motors being main work horses in many industrial environments are known to be impacted in the presence of supply voltage unbalanced system conditions. On the other hand they tend to attenuate pre-existing voltage unbalance (VU) levels at the point of connection thus acting as compensators. Presence of VU causes induction motors to produce unwanted negative torque levels and draw considerably large unbalanced currents. These negative impacts on the performance of induction motors are well documented in the literature. Reduction in motor efficiency due to negative torque and speed drop is demonstrated in [1]. Premature motor failure

U. Jayatunga, S. Perera and P. Ciufo are with the School of Electrical, Computer and Telecommunications Engineering, University of Wollongong, and are members of the Endeavour Energy Power Quality and Reliability Centre, NSW 2522, Australia (email: sarath@uow.edu.au).

NOTICE: this is the authors' version of a work that was accepted for publication in the POWERCON proceedings. Changes resulting from the publishing process, such as peer review, editing, corrections, structural formatting, and other quality control mechanisms may not be reflected in this document. Changes may have been made to this work since it was submitted for publication. A definitive version was subsequently published in the Proceedings of the IEEE International Conference on Power Systems Technology, Oct 2012, DOI:10.1109/PowerCon.2012.6401337 caused by extra heating associated with unbalanced currents are documented in [2]. Derating of induction motors [3] [4], increase of losses and the negative effects on insulation life [5] and performance of protective relays used in induction motors [6] are further areas investigated under unbalanced supply voltages. Definitions, related standards, causes and mitigation techniques related to voltage unbalance are further discussed in [7] [8]. However, little work exists in relation to the quantification of the $\mathrm{VU}$ attenuation provided by induction motors at a point of connection (POC) [9].

Voltage unbalance should be managed in a systematic manner to maintain electromagnetic compatibility levels of the power system. In this regard, IEC/TR61000-3-13:2008 [10] provides guiding principles to system owners and operators to determine the connection requirements of unbalanced installations to power systems. VU emission allocation methodology prescribed in [10] identifies that $\mathrm{VU}$ arises as a result of the two sources, (a) asymmetrical load distribution and (b) inherent system asymmetries. Hence the global VU emission allowance which is calculated based on emission absorption capacity of the system is apportioned between these two sources of unbalance using 'Kue factor' approach [10] [11]. Further to this, a new deterministic approach is presented in [12] to assess individual VU emission contributions made by different sources of unbalance at the POE at the post connection stage of installations. New methodology extends the preliminary work completed on compliance assessment of unbalanced installations in the CIGRE/CIRED C4.109 Technical Brochure on emission assessment techniques [13]. The new assessment criteria is based on complex VU factors which separates the total VU emission at the POC into its constituent components irrespective of the balanced or unbalanced nature of power system components. Different load configurations (passive loads, induction motor loads and mixed loads) are considered separately in developing VU emission assessment methodology. This methodology also quantifies the VU emission attenuation provided by three-phase induction motors at the POE using known system parameters as summarised in Section II. Preliminary work indicates that this emission attenuation is not constant for a given induction motor but it varies with the loading level on the induction motor in addition to variabilities which arise as a result of other factors. This paper investigates the effect of loading level on the VU emission attenuation at the POC based on the findings of [12]. An aggregated induction motor model is presented as an extended work to the VU assessment methodology given 
in [12] to evaluate $\mathrm{VU}$ emission of a group of induction motors which enables the comparison of emission contributions made by different motor groups. Further, impacts of different loading levels on the emission attenuation are investigated under the present context.

The paper is structured as follows; Section II contains a review of the $\mathrm{VU}$ emission assessment techniques presented in [12] relation to induction motors and the proposed theoretical basis for the aggregated induction motor model. VU attenuation provided by induction motors is investigated and presented in Section III. Impact of different loading levels on the motor on the total VU emission is presented in Section IV. Conclusions drawn from the study are given in Section V.

\section{VU EMISSION ASSESSMENT OF INDUCTION MOTORS}

A. Review of VU emission assessment criteria given in [12]

According to IEC/TR61000-3-13:2008 [10], the unbalance emission of an installation is the magnitude of the negative sequence voltage unbalance factor $\left(V U F=\left|\frac{U_{2}}{U_{1}}\right|\right)$ which the installation gives rise to at the point of evaluation $(\mathrm{POE})^{1}$. The approach given in CIGRE/CIRED report on emission assessment techniques [13] is to evaluate unbalance emission levels based on pre-connection $\left(U_{2, \text { pre-connection }}\right)$ and postconnection $\left(U_{2, \text { post-connection }}\right)$ voltage measurements at the POE. Accordingly, the resultant VU emission caused by the connection of $i_{t h}$ installation $\left(U_{2, i}\right)$ can be established as given by (1).

$$
U_{2, i}=U_{2, \text { post-connection }}-U_{2, \text { pre-connection }}
$$

$U_{2, i}$ in (1) can be further expanded as a summation of the individual contributions made by the asymmetrical load $\left(U_{2, i(\text { load })}\right)$ and the asymmetrical line $\left(U_{2, i(\text { line })}\right)$. This gives the post-connection VU emission at the POE with its constituent parts identifying different sources of unbalance as given by (2).

$U_{2, \text { post-connection }}=K \cdot U_{2, \text { pre-connection }}+U_{2, i(\text { load })}+U_{2, i(\text { line })}$

where $K$ is a general complex scaling factor.

The generalised equation given in (2) forms the basis for evaluating the individual emission contributions made by the asymmetry of the installation, asymmetry of the upstream network and asymmetry of the upstream source on the total VU emission at the POE. The linearity property of negative sequence variables [10], [9] is employed in establishing the new methodology for the separation of different VU emission contributors. That is, the resultant negative sequence voltage at the POE which arises as a result of the interaction of various sources of unbalance is equal to the phasor summation of the negative sequence components which arise due to individual sources of unbalance at the POE.

Referring to the radial power system as shown in Fig. 1, sequence domain analysis is used to develop generalised postconnection emission assessment criteria. Naturally, three-phase

\footnotetext{
${ }^{1}$ IEC/TR61000-3-13:2008 considers that the zero sequence VU can be controlled through system design and maintenance
}

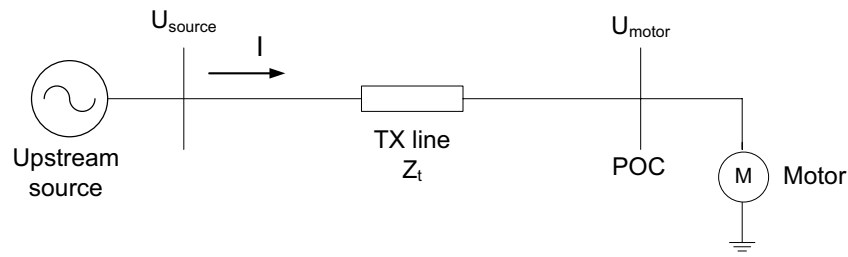

Fig. 1. Radial power system

induction motor loads do not possess any inherent unbalance other than the fact that their operation is affected by the supply source unbalance and hence the specific requirement with induction motors is to examine their behaviour on $\mathrm{VU}$ emission compensation at the POE.

For VU emission assessment studies, three-phase induction motor can be represented by three decoupled impedances in the sequence domain. Total VU emission vector at the POE is then evaluated as shown in (3) establishing positive and negative sequence voltage/current relationships with sequence impedance terms of the upstream network [12].

$$
\begin{aligned}
V U F_{\mathrm{POE}}=\left(\frac{Z_{2, m}}{Z_{1, m}}\right) & \left(\frac{Z_{1, m}+Z_{11, t}}{Z_{2, m}+Z_{22, t}}\right) V U F_{\text {source }} \\
& -\left(\frac{Z_{2, m}}{Z_{1, m}}\right)\left(\frac{Z_{21, t}}{Z_{22, t}+Z_{2, m}}\right)
\end{aligned}
$$

where $V U F_{\text {source }}$ is the upstream source voltage unbalance factor which can be calculated using pre-connection voltage measurements at the POE, $Z_{x y, t}$ is the sequence impedance of the transmission line, $Z_{x, \mathrm{~m}}$ is the sequence impedances of the motor ${ }^{2}$.

As shown in (3), the two terms on the RHS can be described as the upstream source unbalance contribution or the effective upstream source unbalance (as affected by the induction motor) $\left(V U F_{\mathrm{POE}, \mathrm{IM}}\right)$ and asymmetrical line contribution $\left(V U F_{\text {line }}\right)$. Note that there is no term corresponding to the load as the induction motor is considered as a symmetrical load. The VU emission improvement that arise as a result of the connection of induction motor on an already unbalanced supply system (ie. $V U F_{\mathrm{POE}, \mathrm{IM}}$ ) can be noted by considering the special case where the transmission line is symmetrical (i.e., $Z_{21, t}=0$ ). For this case, the voltage unbalance at the POE is the source voltage unbalance level $\left(V U F_{\text {source }}\right)$, scaled by a factor $\left(\frac{Z_{2, m}}{Z_{1, m}}\right)\left(\frac{Z_{1, m}+Z_{11, t}}{Z_{2, m}+Z_{22, t}}\right)$. This scaling factor can be shown to have a magnitude less than unity and incorporates positive and negative sequence impedances of the line and the motor. Similarly, the influence of the asymmetrical supply network (line) on the total unbalance (ie. $V U F_{\text {line }}$ ) can be evaluated considering a balanced upstream source condition (ie. $V U F_{\text {source }}=0$ ) as given by $-\left(\frac{Z_{2, m}}{Z_{1, m}}\right)\left(\frac{Z_{21, t}}{Z_{22, t}+Z_{2, m}}\right)$. Extensive simulations carried out in relation to induction motor unbalance studies have shown that a significant phase shift is not associated between $V U F_{\text {source }}$ and $V U F_{P O E, I M}$ and

\footnotetext{
${ }^{2} x$ and $y$ are replaced by 1 and 2 which stand for positive sequence and negative sequence respectively.
} 
hence the scaling factor $\left(\left(\frac{Z_{2, m}}{Z_{1, m}}\right)\left(\frac{Z_{1, m}+Z_{11, t}}{Z_{2, m}+Z_{22, t}}\right)\right)$ can be treated as a scalar quantity.

\section{B. VU emission assessment of an aggregated induction motor model}

Since induction motors can be represented by three decoupled impedances in the sequence domain, presence of multiple machines at the same POE under unbalanced supply systems can be visualised as shown in Fig. 2 .
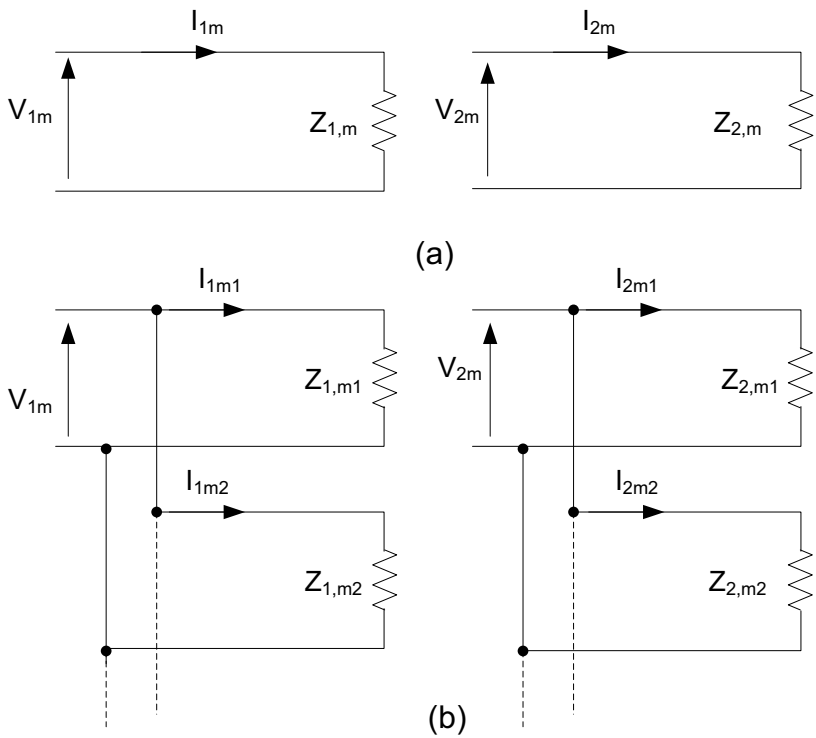

(a)

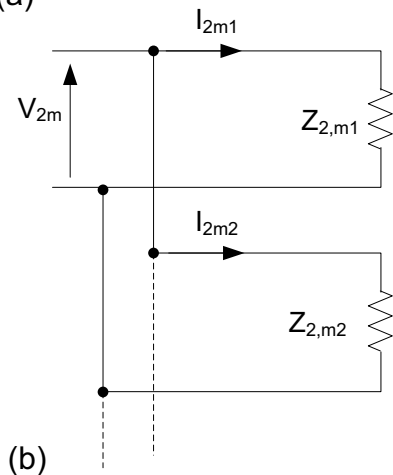

Fig. 2. Induction motor equivalent circuit under unbalance voltages; (a) Single motor representation, (b) multiple motor representation

Referring to Fig. 2, effective positive sequence $\left(Z_{1, \text { meff } f}\right)$ and negative sequence $\left(Z_{2, \text { meff }}\right)$ motor impedances of the group of motors (say $n$ number of parallel connected motors) can be evaluated as follows:

$$
\begin{aligned}
& Z_{1, m e f f}=Z_{1, m 1} / / Z_{1, m 2} / / Z_{1, m 3} / / \ldots / / Z_{1, m n} \\
& Z_{2, m e f f}=Z_{2, m 1} / / Z_{2, m 2} / / Z_{2, m 3} / / \ldots / / Z_{2, m n}
\end{aligned}
$$

Accordingly, the total VU emission at the POE given in (3) can be modified for a group of induction motors as shown in (6).

$$
\begin{array}{r}
V U F_{\mathrm{POE}}=\left(\frac{Z_{2, \text { meff }}}{Z_{1, \text { meff }}}\right)\left(\frac{Z_{1, \text { meff }}+Z_{11, t}}{Z_{2, \text { meff }}+Z_{22, t}}\right) V U F_{\text {source }} \\
-\left(\frac{Z_{2, \text { meff }}}{Z_{1, \text { meff }}}\right)\left(\frac{Z_{21, t}}{Z_{22, t}+Z_{2, \text { meff }}}\right)
\end{array}
$$

This emission assessment methodology of aggregated induction motor model is utilised in section IV to investigate the VU emission attenuation made by a group of small induction motors against a large motor.

\section{ANALYSIS OF INDUCTION MOTOR OPERATION UNDER UNBALANCED VOLTAGES}

Induction motor performance under unbalanced supply conditions is evaluated over the full range of motor operating slip from standstill $(\operatorname{slip}=1)$ to no load operation $(\operatorname{slip}=0)$ in order to examine the impact of induction motor loading level on VU attenuation (see Section IV). In this regard, a simplified power system (see Fig. 1) is simulated considering a special case of symmetrical transmission line and a known upstream unbalanced source. Details of the radial power system is as follows:

- System details: $12.47 \mathrm{kV}, 60 \mathrm{~Hz}$, three-wire

- $12.47 \mathrm{kV}, 5 \mathrm{~km}$ transposed line: Calculated line impedance matrix $\left(\left[Z_{a b c}\right] / \mathrm{km}\right)$

$$
\left[\begin{array}{ccc}
0.249+j 0.875 & 0.059+j 0.498 & 0.059+j 0.498 \\
0.059+j 0.498 & 0.249+j 0.875 & 0.059+j 0.498 \\
0.059+j 0.498 & 0.059+j 0.498 & 0.249+j 0.875
\end{array}\right]
$$

- Induction motor loads: 4-pole, $60 \mathrm{~Hz}$, three-phase induction motors (2.3 kV $2250 \mathrm{hp}, 2.3 \mathrm{kV} 500 \mathrm{hp}$ and 0.460 $\mathrm{kV} 50 \mathrm{hp}$ ) of which the equivalent circuit parameters are given in Appendix A.

- Motor service transformers: 12.47/2.3 kV 3MVA, 12.47/0.46 kV 0.5 MVA three-phase two-winding Yg-Yg connected transformers, leakage reactance of $5 \% \mathrm{pu}$.

Referring to Fig. 1 (simplified system with balanced line), positive and negative sequence voltages at the source end

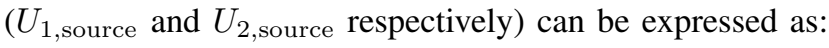

$$
\begin{aligned}
& U_{1, \text { source }}=\left(Z_{1, m}+Z_{11, t}\right) I_{1, m} \\
& U_{2, \text { source }}=\left(Z_{2, m}+Z_{22, t}\right) I_{2, m}
\end{aligned}
$$

where; $I_{1, m}$ and $I_{2, m}$ are positive and negative sequence currents flowing in the system respectively. Positive and negative sequence impedances of the motor $\left(Z_{1, m}\right.$ and $\left.Z_{2, m}\right)$ which are characterised by the motor parameters and operating slip can be established as shown by (9) and (10) respectively referring to the steady state equivalent circuit of an induction motor [4].

$$
\begin{aligned}
& Z_{1, m}=r_{s}+j x_{s}+j x_{m} / /\left(\frac{r_{r}^{\prime}}{s_{1}}+j x_{r}^{\prime}\right) \\
& Z_{2, m}=r_{s}+j x_{s}+j x_{m} / /\left(\frac{r_{r}^{\prime}}{s_{2}}+j x_{r}^{\prime}\right)
\end{aligned}
$$

where $s_{1}$ is the positive sequence slip which is equal to motor operating slip $(s)$ and $s_{2}$ is the negative sequence slip given by $2-s$.

Fig. 3 shows the variation of both magnitude and phase angle of $Z_{1, m}$ and $Z_{2, m}$ over the range of slip from 1 to 0 for the $2.3 \mathrm{kV}, 2250 \mathrm{hp}$ three-phase induction motor. As expected, under locked rotor condition, magnitudes of the motor impedances have equal values $\left(Z_{1, m 0}=Z_{2, m 0}=\right.$ $0.14 \mathrm{pu}$ ) which can be calculated using (11). The relevant phase angles of both impedances are close to 90 degrees as expected. However, as the motor builds up its normal operating conditions, magnitude of $Z_{1, m}$ is increases whereas $\left|Z_{2, m}\right|$ 
stays almost constant as expected at $\left|Z_{2, m 0}\right|$ since the term (2$s$ ) does not have a significant influence on $Z_{2, m}$. Similarly, the phase angle associated with $Z_{2, m}$ remains constant throughout the range of slip values considered.

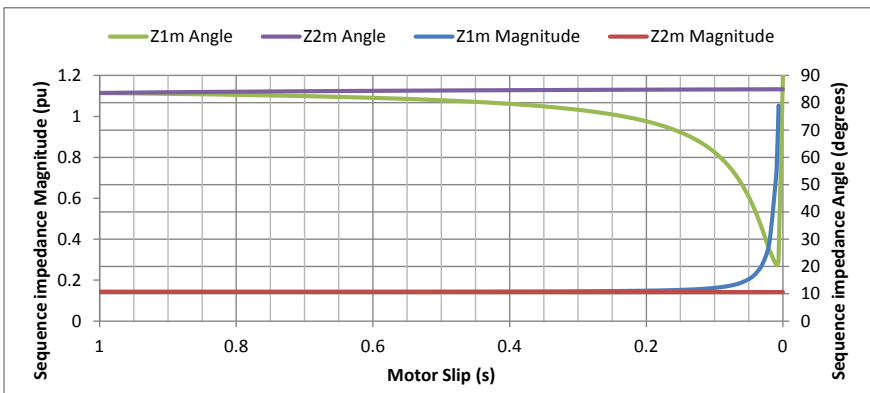

Fig. 3. Sequence impedance $\left(Z_{1, m}\right.$ and $\left.Z_{2, m}\right)$ variation over the motor Slip $(s)-2.3 \mathrm{kV}, 2250 \mathrm{hp}, 3$ phase induction motor

$$
Z_{1, m 0}=Z_{2, m 0}=r_{s}+j x_{s}+j x_{m} / /\left(r_{r}^{\prime}+j x_{r}^{\prime}\right)
$$

Referring to (7) and (8), since upstream source unbalance and line impedances are fixed, motor sequence currents are inversely proportional to respective motor impedances. Therefore, positive sequence current $\left(I_{1}\right)$ decreases while the negative sequence current $\left(I_{2}\right)$ remains constant over the range of slip values considered as shown in Fig 4-(a). The positive and negative sequence voltages at the motor terminal ( $U_{1, \text { motor }}$ and $U_{2, \text { motor }}$ respectively) can be established as the product of its own sequence impedance and the corresponding sequence current flowing in the system (ie. $U_{1, \text { motor }}=Z_{1, m} I_{1}$ and $\left.U_{2 \text {,motor }}=Z_{2, m} I_{2}\right)$. Substitution of $U_{1, \text { motor }}$ and $U_{2, \text { motor }}$ in (7) and (8) respectively shows the variation of sequence voltages at the motor terminal over the operating slip as shown in Fig 4-(b) (ie. $U_{1, \text { source }}=Z_{11, t} I_{1}+U_{1, \text { motor }} ; U_{1, \text { source }}$ and $Z_{11, t}$ are fixed). It is seen from Fig 4-(b) that $U_{1}$ increases as the slip decreases whereas $U_{2}$ stays constant over the range of slip values considered.

These observations lead to make general conclusions with regard to the operation of induction motors under unbalanced supply voltages. The absolute values of negative sequence voltages/currents are not sensitive to the motor operating conditions (ie. locked rotor, no load or full load conditions), but positive sequence quantities vary over the operating conditions which can influence the voltage unbalance at the POE.

\section{Voltage unbalance EMission atTEnUATION CAUSED BY INDUCTION MOTORS}

The VU emission at the POE in terms of VU factor given by $\frac{U_{2, \text { motor }}}{U_{1, \text { motor }}}$ can be seen to reduce from the pre-existing unbalance level ( $V U F_{\text {source }}$ ) as the motor speeds up and reaches steady state operation. When the motors are lightly loaded (towards $s \approx 0$ ) the improvement in the voltage unbalance factor at the POE arises as a result of the increase in $U_{1, \text { motor }}$ and not because of a reduction in $U_{2, \text { motor }}$. Following sub sections consider the impact of loading level of induction motors on

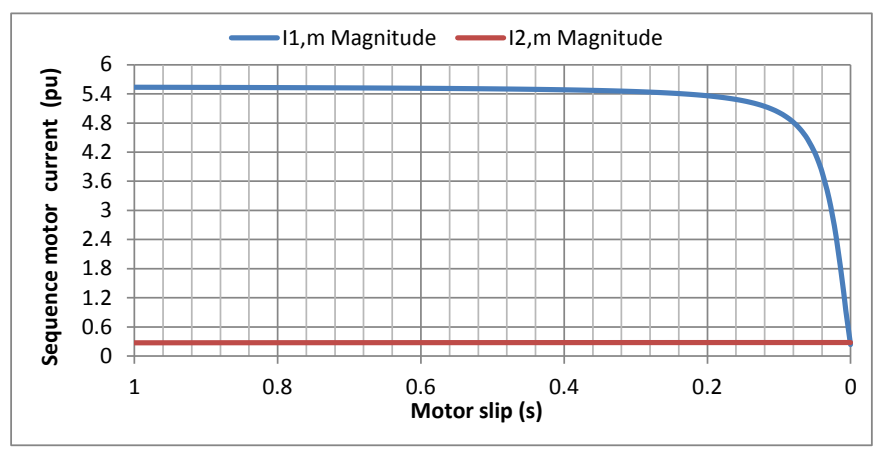

(a)



(b)

Fig. 4. Variation of positive and negative sequence (a). motor current (b). motor voltage over the slip $-2.3 \mathrm{kV}, 2250 \mathrm{hp} 3$-phase induction motor

voltage unbalance emission in greater detail employing the aforementioned theory. Due consideration is given to individual motors and a group of motors having different ratings.

\section{A. Effects of different loading levels on voltage unbalance attenuation}

A sensitivity analysis has been carried out to examine the VU attenuation behaviour exhibited by motors of different sizes on their different loading levels. The VUF at the POE is evaluated using previously considered $12.47 \mathrm{kV}$ radial power system. Three individual motors (2.3 kV $2250 \mathrm{hp}, 2.3 \mathrm{kV} 500$ hp and $460 \mathrm{~V} 50 \mathrm{hp}$ ) were examined in the study. Voltage regulation of the line was set approximately to $2.5 \%$ at full loading of each of the motors used one at a time by adjusting the line length accordingly to make a comparison of the resulting VU attenuation. This refers to a rare case where a very long rural feeder supplying a small motor (eg. 50hp) is to be compared with a shorter rural feeder supplying a slightly bigger motor (eg. $500 \mathrm{hp}$ ). Fig. 5 shows the variation of VU factors at the POE for three different upstream voltage unbalance levels $(1 \%, 3 \%$ and $6 \%)$ as the slip varies from near maximum torque point to zero torque point. The standard torque-slip curves are also superimposed indicating the rated operating point " $\mathrm{A}$ " and the maximum torque point " $\mathrm{B}$ ".

For all three cases, the VU emission caused by respective induction motors are seen to experience an increase when they are fully loaded compared to lightly loaded conditions. That is, maximum emission attenuation is available at the point of no load operation compared to the full load operating point. Further, emission attenuation levels corresponding to 
all three motors at their respective rated slip conditions are seen to be approximately equal (for $6 \%$ upstream unbalance level, $V U F_{P O E} \approx 5 \%$ ) although the motor power ratings are different. Normally, pu imdedances of induction motors which are derived based on own motor base are approximately equal $\left(Z_{1, m 1}=Z_{1, m 2}=\ldots\right.$ and $\left.Z_{2, m 1}=Z_{2, m 2}=\ldots\right)$ irrespective of the power rating of the motor. Since the same voltage regulation is maintained in the three cases, pu impedances of the transmission line are also same for the specific line design. This makes the VU attenuation factor $\left(\frac{Z_{2, m}}{Z_{1, m}}\right)\left(\frac{Z_{1, m}+Z_{11, t}}{Z_{2, m}+Z_{22, t}}\right)$ to be almost constant making resultant unbalance at the POE approximately the same for all three cases. Therefore, emission attenuation obtained at the rated slip depends on the line loading and impedance characteristics (line design) of the line as well.
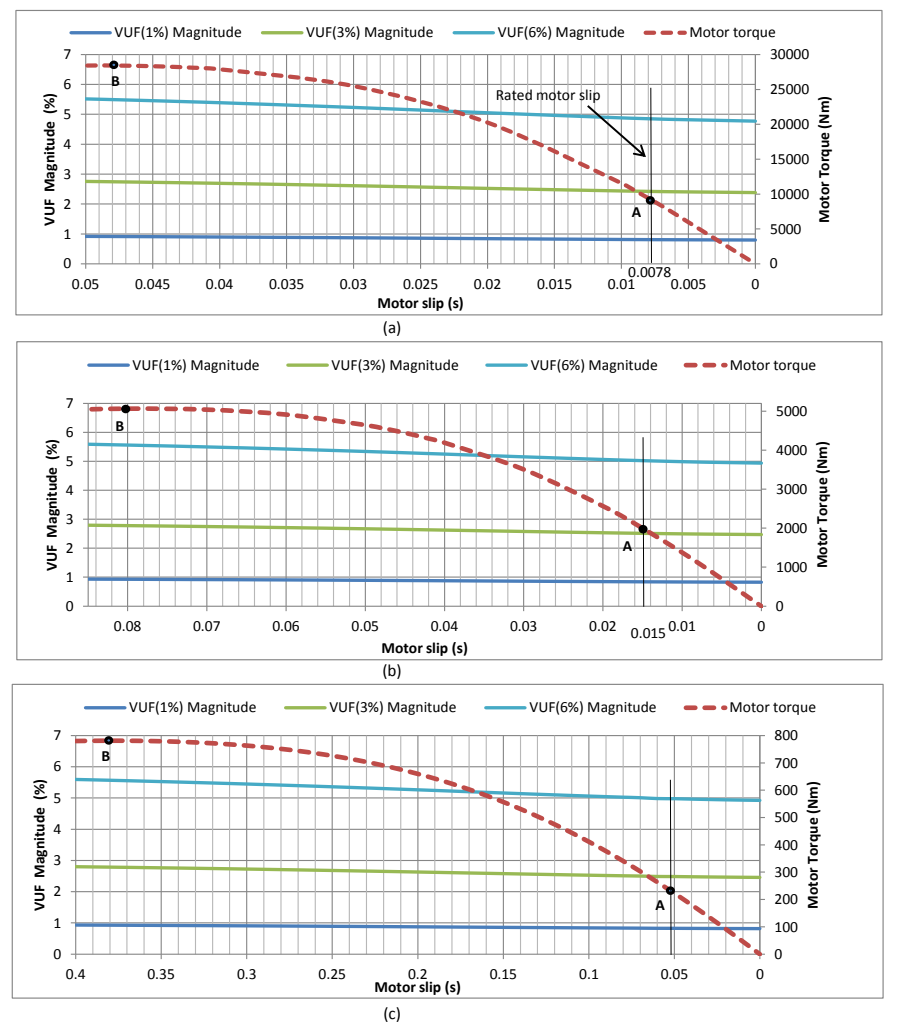

Fig. 5. Variation VU factors at the POE over the slip for different upstream VU emission levels. (a) $2.3 \mathrm{kV}, 2250 \mathrm{hp}$ motor (b) $2.3 \mathrm{kV}, 500 \mathrm{hp}$ motor (c) $460 \mathrm{~V}, 50 \mathrm{hp}$ motor

\section{B. VU attenuation made by group of induction motors}

Modified VU emission assessment criteria for an aggregated motor model given in (6) was used to evaluate the emission contribution given by a group of induction motors at the POE. This study facilitates the comparison of emission levels that arise due to different motor groups (ie, one large motor against a group of small motors equivalent in total power rating in both cases). Two independent induction motor groups of same power capacity connected to the $12.47 \mathrm{kV}$ radial power system (one group at a time) discussed in Section III is considered with an untransposed transmission line (line impedance matrix is given below).
Calculated untransposed line impedance matrix $\left(\left[Z_{a b c}\right] / \mathrm{km}\right)$

$$
\left[\begin{array}{ccc}
0.249+j 0.875 & 0.059+j 0.498 & 0.059+j 0.446 \\
0.059+j 0.498 & 0.249+j 0.875 & 0.059+j 0.498 \\
0.059+j 0.446 & 0.059+j 0.498 & 0.249+j 0.875
\end{array}\right]
$$

Two case studies are presented below considering different power capacities and rated motor voltages. Simulations were carried out using both PSCAD/EMTDC and DigSILENT PowerFactory simulation platforms.

1) Case I: Rated motor voltages are same in the considered motor group: VU emission contribution given by $2.3 \mathrm{kV}$, $2 \mathrm{X} 2,250 \mathrm{hp}$ induction motors is compared with that of 2.3 $\mathrm{kV}, 9 \mathrm{X} 500 \mathrm{hp}$. Total power rating of the motor group is 4,500 hp.

2) Case II: Rated motor voltages are different in the considered motor group: VU emission contribution given by 2.3 $\mathrm{kV}, 500 \mathrm{hp}$ induction motor is compared with that of $0.46 \mathrm{kV}$ $10 \mathrm{X} 50 \mathrm{hp}$ motors. Total power rating of the motor group is $500 \mathrm{hp}$.

Application of (3) and (6) allows decomposition of the total VU at the POE into its constituent parts: (a) Modified upstream source unbalance $\left(V U F_{P O E, I M}\right)$ and (b) asymmetrical line contribution $\left.\left(V U F_{\text {line }}\right)\right)$ which are tabulated in Tables I and II respectively for the two cases discussed above.

The results show that the VU emission contributions made by different motor groups of same power capacity in the same case study (in Case I: 2X2250 hp and 9X500 hp motors or in Case II: 1 X500 hp and 10X50 hp motors) are approximately equal. This leads to make a general observation that the resultant emission contribution of induction motors at the POE is governed by the total power rating of induction motors for a given power network irrespective of the motor group (operating voltage or number of motors connected or size of individual motors).

\section{Conclusions}

Induction motor performance under unbalanced supply system conditions was investigated in order to establish the impact of induction motor loading level on total VU emission attenuation at the POE. Variation in the motor operating slip impacts on the positive sequence voltage/current at the POE whereas the negative sequence quantities remain almost constant. This results in a high VUF under motor locked rotor conditions whereas a high CUF is the result under normal motor operating conditions.

Sensitivity studies on the VU emission have shown that the VU attenuation decreases as the motor loading level is increased. Induction motors with different power capacities are shown to give rise to same emission levels for a given line design and equally loaded line while maintaining same voltage regulation of the line. Further, the VU emission contribution made by a group of small induction motors at the POE was shown to be nearly equal to the emission contribution made by a single large induction motor of the same total power capacity irrespective of motor operating voltage. 
TABLE I

COMPARISON OF VU EMISSION CAUSED BY DIFFERENT INDUCTION MOTOR GROUPS - $2.3 \mathrm{KV}, 2 \mathrm{X} 2250$ HP AND 9 X500 HP MOTORS

\begin{tabular}{|c|c|c|c|c|c|c|c|}
\hline \multirow[t]{2}{*}{ \# } & \multirow[t]{2}{*}{$V U F_{\text {source }}$} & \multicolumn{2}{|l|}{$V U F_{\mathrm{POE}} \%$} & \multicolumn{2}{|l|}{$V U F_{\text {line }} \%$} & \multicolumn{2}{|c|}{$V U F_{P O E, I M} \%$} \\
\hline & & $\begin{array}{l}\text { 2X2250 hp } \\
\text { motors }\end{array}$ & $\begin{array}{l}\text { 9X500 hp } \\
\text { motors }\end{array}$ & $\begin{array}{l}\text { 2X2250 hp } \\
\text { motors }\end{array}$ & $\begin{array}{l}\text { 9X500 hp } \\
\text { motors }\end{array}$ & $\begin{array}{l}\text { 2X2250 hp } \\
\text { motors }\end{array}$ & $\begin{array}{l}9 \mathrm{X} 500 \mathrm{hp} \\
\text { motors }\end{array}$ \\
\hline $\mathrm{a}$ & $0.0 \angle 0$ & $0.26 \angle-166$ & $0.28 \angle-169$ & $0.26 \angle-166$ & $0.28 \angle-169$ & $0 \angle 0$ & $0 \angle 0$ \\
\hline $\mathrm{b}$ & $1.75 \angle 30$ & $0.95 \angle 43$ & $1.01 \angle 42$ & $0.26 \angle-167$ & $0.28 \angle-170$ & $1.19 \angle 36$ & $1.26 \angle 35$ \\
\hline $\mathrm{c}$ & $2.33 \angle 29$ & $1.35 \angle 41$ & $1.43 \angle 40$ & $0.27 \angle-167$ & $0.29 \angle-170$ & $1.58 \angle 37$ & $1.68 \angle 35$ \\
\hline
\end{tabular}

TABLE II

COMPARISON OF VU EMISSION CAUSED B Y DIFFERENT INDUCTION MOTOR GROUPS - 2.3 KV, 1X500 HP AND 460 V, $10 X 50$ HP MOTORS

\begin{tabular}{|c|c|c|c|c|c|c|c|}
\hline \multirow[t]{2}{*}{$\#$} & \multirow[t]{2}{*}{$V U F_{\text {source }}$} & \multicolumn{2}{|l|}{$V U F_{\mathrm{POE}} \%$} & \multicolumn{2}{|l|}{$V U F_{\text {line }} \%$} & \multicolumn{2}{|c|}{$V U F_{P O E, I M} \%$} \\
\hline & & $\begin{array}{l}\text { 1X500 hp } \\
\text { motors }\end{array}$ & $\begin{array}{ll}10 X 50 & \mathrm{hp} \\
\text { motors } & \end{array}$ & $\begin{array}{l}1 \mathrm{X} 500 \mathrm{hp} \\
\text { motors }\end{array}$ & $\begin{array}{ll}10 X 50 & \mathrm{hp} \\
\text { motors } & \\
\end{array}$ & $\begin{array}{l}1 \mathrm{X} 500 \mathrm{hp} \\
\text { motors }\end{array}$ & $\begin{array}{l}\text { 10X50 hp } \\
\text { motors }\end{array}$ \\
\hline $\mathrm{a}$ & $0.0 \angle 0$ & $0.041 \angle-173$ & $0.045 \angle-177$ & $0.041 \angle-173$ & $0.045 \angle-177$ & $0 \angle 0$ & $0 \angle 0$ \\
\hline $\mathrm{b}$ & 0.5 & $0.47 \angle 33$ & 0.45 & $0.041 \angle-173$ & $0.046 \angle-177$ & $0.52 \angle 31$ & $0.49 \angle 29$ \\
\hline $\mathrm{c}$ & $2.33 \angle 29$ & $2.03 \angle 31$ & $1.93 \angle 28$ & $0.041 \angle-173$ & $0.046 \angle-177$ & $2.07 \angle 30$ & $1.96 \angle 29$ \\
\hline
\end{tabular}

\section{APPENDIX A}

\section{$60 \mathrm{~Hz}, 4$-POLE INDUCTION MOTOR PARAMETERS [14]}

Details of induction motors used in this work were obtained from [14] and are given in Table III.

TABLE III

INDUCTION MOTOR PARAMETERS

\begin{tabular}{|l|l|l|l|}
\hline & $\begin{array}{l}50 \quad \text { hp } \\
\text { motor }\end{array}$ & $\begin{array}{l}500 \text { hp } \\
\text { motor }\end{array}$ & $\begin{array}{l}2250 \text { hp } \\
\text { motor }\end{array}$ \\
\hline Rated voltage- $V_{\text {rated }}(\mathrm{V})$ & 460 & 2300 & 2300 \\
\hline rated speed $(\mathrm{rpm})$ & 1705 & 1773 & 1786 \\
\hline Rated current $(\mathrm{A})$ & 46.8 & 93.6 & 421.2 \\
\hline stator resistance $-r_{s}(\Omega)$ & 0.087 & 0.262 & 0.029 \\
\hline Stator reactance $-X_{l s}(\Omega)$ & 0.302 & 1.206 & 0.226 \\
\hline Rotor resistance $-r_{r}^{\prime}(\Omega)$ & 0.228 & 0.0187 & 0.022 \\
\hline Rotor reactance $-X_{l r}^{\prime}-(\Omega)$ & 0.302 & 1.206 & 0.226 \\
\hline Mag. reactance $-X_{M}(\Omega)$ & 13.08 & 54.02 & 13.04 \\
\hline Motor inertia $-J\left(\mathrm{kgm}^{2}\right)$ & 1.662 & 11.06 & 63.87 \\
\hline
\end{tabular}

\section{REFERENCES}

[1] J E Williams, "Operation of 3-Phase Induction Motors on Unbalanced Voltages", Power Apparatus and Systems, Part III. Transactions of the American Institute of Electrical Engineers, vol.73, no.1, pp.125-133, Jan. 1954.

[2] B N Gafford, W C Duesterhoeft, C C Mosher, "Heating of Induction Motors on Unbalanced Voltages", Power Apparatus and Systems, Part III. Transactions of the American Institute of Electrical Engineers, vol.78, no.3, pp.282-286, April 1959.

[3] M M Berndt, N L Schmitz, "Derating of polyphase induction motors operated with unbalanced line voltages", Power Apparatus and Systems, Part III. Transactions of the American Institute of Electrical Engineers, vol.81, no.3, pp.680-683, April 1962

[4] P Pillay, P Hofmann, M Manyage, "Derating of induction motors operating with a combination of unbalanced voltages and over or undervoltages", IEEE Trans. on Energy Conversion, vol.17, no.4, pp. 485- 491, Dec 2002.

[5] R F Woll, "Effect of Unbalanced Voltage on the Operation of Polyphase Induction Motors", IEEE Trans. on Industry Applications, vol.IA-11, no.1, pp.38-42, Jan. 1975.

[6] P B Cummings, J R Dunki-Jacobs, R H Kerr, "Protection of Induction Motors Against Unbalanced Voltage Operation", IEEE Trans. on Industry Applications, vol.IA-21, no.3, pp.778-792, May 1985.

[7] A Von Jouanne, B Banerjee "Assessment of voltage unbalance", IEEE Trans. on Power Delivery, vol.16, no.4, pp.782-790, Oct 2001.

[8] J Faiz, H Ebrahimpour, P Pillay, "Influence of unbalanced voltage on the steady-state performance of a three-phase squirrel-cage induction motor", IEEE Trans. on Energy Conversion, vol.19, no.4, pp. 657- 662, Dec. 2004.
[9] Prabodha Paranavithana, 'Contributions Towards the Development of the Technical Report IEC/TR 61000-3-13 on Voltage Unbalance Emission Allocation', Ph.D. dissertation, School of Electrical, Computer and Telecommunications Engineering, University of Wollongong, Australia, March 2009.

[10] 'Electromagnetic compatibility (EMC) - limits - assessment of emission limits for the connection of unbalanced installations to MV, $\mathrm{HV}$ and EHV power systems', Technical report IEC/TR 61000-3-13, Ed. 1, International Electrotechnical Commission, 2008.

[11] Upuli Jayatunga, Sarath Perera and Philip Ciufo, "Voltage unbalance management in power systems based on IEC 61000-3-13:2008: implications on the use of ' $\mathrm{k}_{\mathrm{uE}}$ factor'", Accepted for publication in Proc. 15th International Conference on Harmonics and Quality of Power, ICHQP 2012, Hong Kong, June 2012.

[12] Upuli Jayatunga, Sarath Perera and Philip Ciufo, "Voltage unbalance emission assessment in radial power systems", IEEE Trans. on Power Delivery, vol.27, no.3, pp.1653-1661, July 2012.

[13] 'Review of Disturbance Emission Assessment Techniques', CIGRECIRED C4.109 Technical Brochure, June 2011.

[14] Paul C. Krause, Oleg Wasynczuk, Scott D. Sudhoff, 'Analysis of Electric Machinery and Drive Systems'Second Ed., John Wiley and Sons Inc., pp165, 2002. 